\title{
Comunicação \\ Uso de biofertilizante na produção de mudas de repolho
}

\author{
Cinthia Röder ${ }^{*}$, Átila Francisco Mógor ${ }^{2}$, Vivian Jaskiw Szilagyi-Zecchin ${ }^{3}$, \\ Eliseu Geraldo dos Santos Fabbrin', Luiz Gabriel Gemin ${ }^{5}$ \\ http://dx.doi.org/10.1590/0034-737X201562050012
}

\begin{abstract}
RESUMO
A utilização de produtos biofertilizantes, como fermentados bacterianos, contendo aminoácidos, é pouco estudada na produção de mudas de hortaliças, especialmente no sistema orgânico. Neste trabalho, o objetivo foi avaliar o efeito da aplicação foliar de um fermentado bacteriano do melaço da cana, contendo $30 \%$ do aminoácido ácido Lglutâmico, no desenvolvimento de mudas de repolho. Os tratamentos, constituídos por quatro repetições, eram compostos por concentrações do fermentado $\left(0 ; 0,1 ; 0,2 ; 0,4\right.$ e $\left.0,8 \mathrm{~mL} \mathrm{~L}^{-1}\right)$ aplicadas nas folhas, em intervalos de sete ou de 14 dias. Aos 35 dias após a semeadura, foram determinados o índice relativo de clorofila, a área foliar e o volume do sistema radicular. O fermentado bacteriano promoveu incrementos do índice relativo de clorofila, da área foliar e do volume radicular, quando aplicado com intervalos de 14 dias, e incremento do volume radicular, quando aplicado com intervalos de sete dias. Ocorreu redução da área foliar, quando aplicado em concentrações superiores a $0,2 \mathrm{ml} \mathrm{L}^{-1}$, com intervalos de sete dias. O biofertilizante incrementa o desenvolvimento de mudas de repolho.
\end{abstract}

Palavras-chave: Brassica oleracea var. capitata L., aminoácido, produção orgânica, ácido L-glutâmico, clorofila.

\section{ABSTRACT}

\section{Biofertilizers in cabbage seedling production}

The use of biofertilizers such as bacterial fermentation broth containing amino acids is poorly studied in the production of organic seedlings. The aim of this study was to test the effect of foliar spraying of the sugarcane fermented broth containing 30\% of L- glutamic acid, on the growth of cabbage seedlings, without using synthetic fertilizers. The treatments consisted of foliar spraying with solutions containing different concentrations of fermented broth $\left(0,0.1,0.2,0.4\right.$ and $\left.0.8 \mathrm{~mL} \mathrm{~L}^{-1}\right)$, in four repetitions, in intervals of seven or fourteen days. At 35 days after sowing, the following variables were determined: chlorophyll relative index, leaf area and root volume. The fermented broth increased the chlorophyll relative index, leaf area and root volume when applied in intervals of fourteen days, and increased the root volume when applied in intervals of seven days. There was a reduction in leaf area when applied in concentrations higher than $0.2 \mathrm{ml} \mathrm{L}^{-1}$ in intervals of seven days. The biofertilizer enhanced the development of cabbage seedlings.

Key words: Brassica oleracea var. capitata L., aminoacid, organic production, L-glutamic acid, chlorophyll.

\footnotetext{
Submetido em 05/06/2014 e aprovado em 03/08/2015.

${ }^{1}$ Universidade Federal do Paraná, Departamento de Fitotecnia e Fitossanitarismo, Curitiba, Paraná, Brasil. cinthia.roder@gmail.com

${ }^{2}$ Universidade Federal do Paraná, Departamento de Fitotecnia e Fitossanitarismo, Curitiba, Paraná, Brasil. afmogor@gmail.com

${ }^{3}$ Universidade Federal do Paraná, Departamento de Fitotecnia e Fitossanitarismo, Curitiba, Paraná, Brasil. vivian.szilagyi@gmail.com

${ }^{4}$ Universidade Federal do Paraná, Departamento de Fitotecnia e Fitossanitarismo, Curitiba, Paraná, Brasil. eliseugsfabbrin@yahoo.com.br

${ }^{5}$ Universidade Federal do Paraná, Departamento de Fitotecnia e Fitossanitarismo, Curitiba, Paraná, Brasil. Gemin1988@ hotmail.com

*Autora para correspondência: cinthia.roder@gmail.com
} 


\section{INTRODUÇÃO}

Um dos maiores desafios para a agricultura é o estabelecimento de sistemas agrícolas sustentáveis, evidenciando-se o sistema orgânico como importante alternativa. Por essas razões, há a necessidade da utilização de produtos que estejam em conformidade com a legislação da produção orgânica, como os biofertilizantes, os quais, de acordo com Bezerra et al. (2007), estimulam o crescimento das raízes e o desenvolvimento das plantas, uma vez que são considerados ativadores metabólicos.

Os biofertilizantes são definidos, na Instrução Normativa $n^{\circ} 46$ de 06 de outubro de 2011, como produtos que contêm componentes ativos ou agentes biológicos capazes de atuar, direta ou indiretamente, sobre o todo ou sobre partes das plantas cultivadas, melhorando o desempenho do sistema de produção, e, que sejam isentos de substâncias proibidas pela regulamentação de orgânicos (MAPA, 2012).

Dentre os produtos com possível efeito biofertilizante, estão os obtidos de processos fermentativos, a partir de subprodutos da agroindústria. O caldo fermentado do melaço da cana-de-açúcar pela bactéria Corynebacterium glutamicum, produtora do aminoácido ácido L-glutâmico (Dreyer et al., 2000), enquadra-se nessa classe. No metabolismo vegetal, o ácido Lglutâmico participa do processo de assimilação do nitrogênio, na fotossíntese, e na síntese e ativação da clorofila (Taiz \& Zeiger, 2009). Beale et al. (1975), em trabalho com carbono marcado, comprovaram a absorção foliar do ácido L-glutâmico e sua atuação no metabolismo das plantas, ao ser incorporado ao ácido aminolevulínico (ALA), relacionado com a biossíntese de clorofila.

Apesar dos relatos dos benefícios do uso dos biofertilizantes na agricultura, especialmente no sistema orgânico (Bettiol, 2001), e do conhecimento do papel do ácido L-glutâmico no metabolismo vegetal, ainda são escassas as informações da utilização desses compostos na produção de mudas.

A produção de mudas de alta qualidade constitui uma das etapas mais importantes do sistema produtivo (Silveira et al., 2002), influenciando diretamente o desempenho final das plantas, tanto do ponto de vista nutricional quanto do ciclo do cultivo. Mudas mal formadas comprometem o desenvolvimento das plantas e prolongam seu ciclo, levando a perdas de produção (Guimarães et al., 2002; Reghin et at., 2003; Reghin et al., 2004).

Portanto, neste trabalho, buscou-se determinar o efeito de diferentes doses e de intervalos de aplicação foliar de um fermentado bacteriano, com $30 \%$ do aminoácido ácido L-glutâmico, no desenvolvimento de mudas de repolho.

\section{MATERIAL E MÉTODOS}

O experimento foi conduzido em viveiro de produção de mudas, na Área Experimental de Olericultura Orgânica da Universidade Federal do Paraná, nas coordenadas $25^{\circ} 25^{\prime} \mathrm{S}$ e $49^{\circ} 06^{\prime} \mathrm{O}$, com altitude de 920 metros.

Os tratamentos consistiram em aplicações foliares com concentrações de 0,$1 ; 0,2 ; 0,4$ e $0,8 \mathrm{~mL} \mathrm{~L}^{-1}$ do fermentado de melaço de cana pela bactéria Corynebacterium glutamicum, com $30 \%$ do aminoácido ácido L-glutâmico e 6\% de carbono orgânico (AG30), bem como uma testemunha, com aplicação de água. As aplicações foram realizadas, utilizando-se pulverizador pressurizado com $\mathrm{CO}_{2}$, com pressão constante (45 lib pol $^{-1}$ ) e volume de calda de $100 \mathrm{~mL}$ por bandeja. Uma semana após emergência, iniciaram-se as aplicações, realizadas em duas frequências: a cada sete dias, totalizando-se, com este intervalo, quatro aplicações, ou, a cada 14 dias, resultando em duas aplicações. Ao fim das aplicações, 35 dias após semeadura, foram feitas as avaliações.

$\mathrm{O}$ delineamento experimental foi inteiramente casualizado, em esquema fatorial 5 × 2 , sendo cinco concentrações e dois intervalos (sete e 14 dias), com quatro repetições, constituídas por 100 plantas cada.

Utilizaram-se sementes de repolho 'Mirai', com semeadura realizada no dia 25/03/2011, em bandejas de poliestireno expandido de 200 células, preenchidas com o substrato composto de cama de aviário compostada, associado a casca de pinus compostada, na proporção de 1:3, respectivamente. As bandejas foram mantidas por 35 dias após a semeadura (DAS) em casa de vegetação, do tipo arco com cortinas laterais e cobertura plástica transparente de 150 micras, com dimensões de 7 x 15 $\mathrm{m}$, dotada de irrigação por microaspersão temporizada e bandejas suspensas em estrutura com fios de arame.

Aos 35 DAS, foram selecionadas aleatoriamente dez mudas de cada repetição, sendo analisadas as seguintes variáveis: índice relativo de clorofila (IRC), área foliar (AF) e volume radicular (VR).

Para a avaliação do índice relativo de clorofila, utilizou-se um clorofilômetro manual, com diodos que emitem radiação em $650 \mathrm{~nm}$ (luz vermelha) e 940 nm (radiação infravermelha) (Mógor et al., 2013). Após a mensuração do índice relativo de clorofila, as plantas foram lavadas, para remoção do substrato aderido às raízes, e seccionadas, separando-se parte aérea e sistema radicular. A área foliar e o volume radicular foram analisados por meio do programa computacional WinRhizo $^{\circledR}$, acoplado a um scanner.

Os dados obtidos foram submetidos à análise de variância. Para as características em que foram observadas diferenças significativas, realizou-se a análise de 
regressão. Os dados foram processados pelo programa ASSISTAT, versão 7.6 Beta (Silva, 2008).

\section{RESULTADOS E DISCUSSÃO}

As alterações do índice relativo de clorofila (IRC) das mudas de repolho submetidas a aplicações do fermentado bacteriano, contendo 30\% de ácido L-glutâmico (AG30) (Figura 1), indicam a absorção e metabolização do aminoácido, conforme relatado por Yaronskaya et al. (2006) e Beale et al. (1975), que, quando aplicado por via foliar, é incorporado ao ácido aminolevulínico, e, por consequência, participa da síntese de clorofila (Beale et al., 1975).

O aumento linear do IRC, com o aumento da concentração de AG30, exclusivamente no intervalo de 14 dias entre aplicações (IA14) (Figura 1), sugere que o período para a atuação do aminoácido exógeno na síntese de clorofila seja superior a sete dias, já que, no momento das leituras (35 DAS), passaram-se sete dias da última aplicação com intervalo de sete dias (IA7), sem apresentar-se efeito no IR, e 14 dias das aplicações com IA14, neste caso, apresentando efeito linear em função do aumento da concentração de AG30 (Figura 1).

Assim como as alterações do IC, as alterações da área foliar (AF) no IA14 foram mais bem representadas por uma equação linear, com o aumento da AF em função do aumento da concentração de AG30, enquanto, no IA7, as alterações foram mais bem representadas por uma equação quadrática, com a redução da AF quando a concentração de AG30 foi superior a 0,2 $\mathrm{mL} \mathrm{L}^{-1}$ (Figura 2), o que levou à redução de crescimento dessas plantas.

A importância dos aminoácidos glutamina e glutamato, oriundos do ácido L-glutâmico, no metabolismo do nitrogênio, é bem discutida na literatura, destacandose seu papel na fixação biológica e no transporte do nitrogênio orgânico de fontes para drenos, atuando no crescimento e no desenvolvimento das plantas (Ferreira et

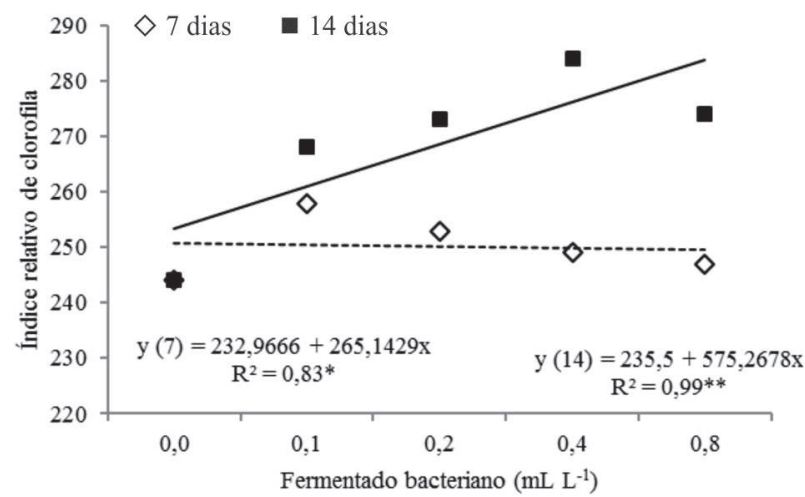

Figura 1: Índice relativo de clorofila de mudas de repolho, em função da frequência de aplicação e das diferentes concentrações de fermentado bacteriano, contendo $30 \%$ de aminoácido ácido L-glutâmico. al., 2002). Mas relatos de redução do crescimento e do desenvolvimento identificados pela redução da AF, em função de concentrações e de intervalos de aplicação de fontes de aminoácidos, não foram encontrados. Já a redução do crescimento das raízes em diferentes espécies vegetais com a aplicação de glutamato foi relatada por Forde \& Lea (2007).

O volume radicular (VR) das mudas de repolho apresentou aumento linear, em função do aumento da concentração de AG30 (Figura 3), diferentemente do relatado por Forde \& Lea (2007). Os aumentos do VR foram semelhantes, no IA7 e no IA14, diferentemente do observado para IRC e AF, indicando que os aumentos do IRC (Figura 1) e da AF (Figura 2), no IA14, não resultaram em aumento do VR. Da mesma forma, a redução da AF no IA7 não limitou o desenvolvimento radicular.

Os resultados do VR são relevantes, ao se considerar que a maior quantidade de raízes propicia maior quantidade de nutrientes absorvidos no intervalo entre o transplante e a formação de novas raízes (Minami, 1995), influenciando diretamente o desempenho final das plantas (Silveira et al., 2002).

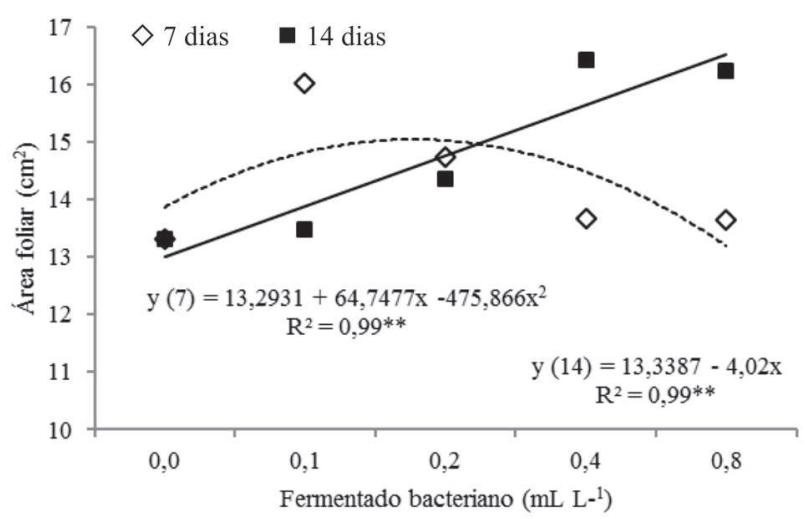

Figura 2: Área foliar $\left(\mathrm{cm}^{2}\right)$ de mudas de repolho, em função da frequência de aplicação e das diferentes concentrações de biofertilizante com $30 \%$ de aminoácido ácido L-glutâmico.

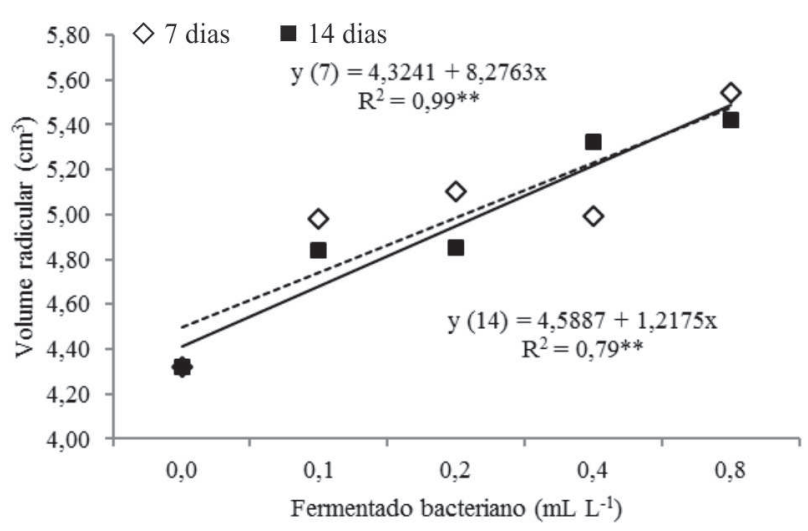

Figura 3: Volume radicular $\left(\mathrm{cm}^{3}\right)$ de mudas de repolho, em função da frequência de aplicação e das diferentes concentrações de biofertilizante com 30\% de aminoácido ácido L-glutâmico. 
Os incrementos obtidos no IA14, para IRC, AF e VR, e no IA7, para VR, pela aplicação foliar de AG30, justificam-se, pois, uma vez metabolizados, os aminoácidos podem suprir parte das necessidades na síntese de proteínas estruturais, além de participarem da síntese de vitaminas e de vários outros compostos, como a clorofila, com efeito direto sobre o desenvolvimento vegetal (Brandão, 2007).

Os resultados deste trabalho indicam que a aplicação foliar de AG30 foi eficiente em promover o crescimento de mudas de repolho, conduzidas em sistema orgânico, dependendo da concentração e dos intervalos de aplicação. Os resultados apontam uma absorção e metabolização do ácido L glutâmico contido no fermentado, principalmente ao alterar o IRC (Figura 1), ressaltando que, além do aminoácido, o AG30 contém 6\% de carbono orgânico e, possivelmente, outros compostos minoritários não identificados, resultantes da fermentação bacteriana. Ficou evidenciado, também, que AG30 pode ser considerado um biofertilizante, ao conter componente ativo capaz de atuar, direta ou indiretamente, sobre o todo ou sobre partes das plantas cultivadas, podendo melhorar o desempenho do sistema de produção.

\section{CONCLUSÕES}

A utilização do fermentado bacteriano com $30 \%$ do aminoácido ácido L-glutâmico promoveu incrementos do índice relativo de clorofila, da área foliar e do volume radicular, quando aplicado por via foliar em mudas de repolho, com intervalos de 14 dias, e incremento do volume radicular, quando aplicado com intervalos de sete dias.

Ocorreu redução da área foliar quando aplicado em concentrações superiores a $0,2 \mathrm{~mL} \mathrm{~L}^{-1}$, com intervalos de sete dias.

\section{REFERÊNCIAS}

Beale S, Gough SP \& Granick S (1975) Biosynthesis of deltaaminolevulinic acid from the intact carbon skeleton of glutamic acid in greening barley. Proceedings of the National Academy of Sciences of the United States of America, 72:2719-272.

Bettiol W (2001) Resultados de pesquisa com métodos alternativos para o controle de doenças de plantas. In: $1^{\circ}$ Encontro de processos de proteção de plantas: controle ecológico de pragas e doenças, Botucatu. Anais, Agroecológica. p.125-135.

Bezerra PSG, Grangeiro LG, Negreiros MZ de \& Medeiros JF de (2007) Utilização de bioestimulante na produção de mudas de alface. Científica, 35:46-50

Brandão RP (2007) Importância dos aminoácidos na agricultura sustentável. São Joaquim da Barra, Informativo BioSoja. p.6-8. (Informativo, 5).

Dreyer A, Coello N \& Mondiel E (2000) Utilización de la metodologia de superfície de respuesta de la optimización de um medio de cultivo para la producción de L-lisin por Corynebacterium glutamicum. Agronomía Tropical, 50:167-88.
Ferreira VM, Magalhães PC, Durães FOM, Oliveira LEM \& Purcino AAC (2002) Metabolismo do nitrogênio associado à deficiência hídrica e sua recuperação em genótipos de milho. Ciência Rural, 32:1317

Forde BG \& Lea PJ (2007) Glutamate in plants: metabolism, regulation, and signaling. Journal of Experimental Botany, 58:2339-2358.

Guimarães VF, Echer MM \& Minami K (2002) Métodos de produção de mudas, distribuição de matéria seca e produtividade de plantas de beterraba. Horticultura Brasileira, 20:505-509.

MAPA - Ministério da Agricultura, Pecuária e Abastecimento (2012) Instrução Normativa MAPA n ${ }^{\circ} 46$ de 06/10/2011 - Estabelece o Regulamento Técnico para os Sistemas Orgânicos de Produção Animal e Vegetal. Disponível em: <http://www.legisweb.com.br/legislacao/ ?id=78910>. Acessado em: 27 de abril de 2012.

Minami K (1995) Produção de mudas de alta qualidade em horticultura. São Paulo, TA Queiroz. 135p.

Mógor AF, Barbizan T, Pauletti V, Oliveira JO \& Bettoni MM (2013) Teores de clorofila em cultivares de tomateiro submetidas a aplicações foliares de magnésio. Pesquisa Agropecuária Tropical, 43:363369.

Reghin MY, Otto RF, Vinne JVD \& Feltrim AL (2003) Tamanho da célula de diferentes bandejas na produção de mudas e no cultivo do pak choi na presença e ausência do agrotêxtil. Scientia Agraria, 4:61-67.

Reghin MY, Otto RF \& Vinne JVD (2004) Efeito da densidade de mudas por célula e do volume da célula na produção de mudas e cultivo da rúcula. Ciência e Agrotecnologia, 28:287-295.

Silva FAS (2008) Sistema de Assistência Estatís-tica - ASSISTAT. Disponível em: <http://www.assistat.com>. Acessado em: 09 de março de 2014.

Silveira EB, Rodrigues VJLB, Gomes AMA, Mariano RLR \& Mesquita JCP (2002) Pó de coco como substrato para produção de mudas de tomateiro. Horticultura Brasileira, 20:211-216.

Taiz L \& Zeiger E (2009) Fisiologia Vegetal. $4^{\mathrm{a}}$ ed. Porto Alegre, Artmed. 848p.

Yaronskaya E, Vershilovskaya I, Poers Y, Alawady AE, Averina N \& Grimm B (2006) Cytokinin effects on tetrapyrrole biosynthesis and photosynthetic activity in barley seedlings. Planta, 224:700-709. 